\title{
LA EVOLUCIÓN PECULIAR DEL ARTE Y LA EVOLUCIÓN CULTURAL
}

\section{Carlos Martínez Gorrirán}

Universidad del País Vasco / Euskal Herriko Unibertsitatea. Dpto. Filosofía de los Valores y Antropología Social

\section{Resumen}

La evolución de la cultura se fundamenta en la evolución natural, pero presenta importantes diferencias que la convierten en una evolución distinta. A su vez, la evolución del arte muestra una lógica peculiar, diferente a la evolución de la ciencia y la sociedad. Los cánones estéticos comienzan y acaban bruscamente tras un periodo más o menos dilatado de tiempo, sin transiciones graduales, formando una comunidad de representación. Ciertas cualidades inmanentes de lo estético, asociadas a la cognición y al funcionamiento de la mente,pueden explicar esta peculiaridad mejor que las teorías biológicas, filosóficas y sociológicas tradicionales. La creación estética es fundamental para desarrollar el pensamiento simbólico básico, sin acumular adaptaciones ni un saber normalizado en paradigmas sucesivos.

\section{Palabras clave: ESTÉTICA, EVOLUCIÓN, HISTORIA DEL ARTE, CÁNON ESTÉTICO, COMUNIDAD DE REPRESENTACIÓN, COGNI- CIÓN, MENTE HUMANA}

\section{THE PARTICULAR EVOLUTION OF ART AND CULTURAL EVOLUTION}

\section{Abstract}

The evolution of culture is based on natural evolution, but it has important differences that make it a distinct development. At the same time, the evolution of art shows a peculiar logic, different from the evolution of science and society. The aesthetic canons begin and end abruptly for a more or less extended period of time, without gradual transitions, forming a community of representation. Certain immanent qualities of the aesthetic, associated with cognition and the functioning of the mind, can explain this peculiarity better than traditional biological, philosophical and sociological theories. The aesthetic creation is fundamental for the development of the basic symbolic thought, without accumulating either adjustments or a knowledge normalized in successive paradigms.

\section{Keywords: AESTHETICS, EVOLUTION, HISTORY OF ART, AESTHETIC CANON, COMMUNITY OF REPRESENTATION, COGNITION, HUMAN MIND}

\footnotetext{
Martínez Gorrirán, Carlos. "La evolución peculiar del arte y la evolución cultura7". AusArt 5(2): 27-39. DOI: 10.1387/ausart.18738
}

\section{AUSART}




\section{1. ¿QUÉ HAY DE EXTRAÑO EN LA HISTORIA DEL ARTE?}

En su Historia de la Pintura Moderna, Herbert Read ([1966] 1984, 12)recurre a una cita de Robin G. Collingwood (1922) para encabezar el primer capítulo: "Para el historiador habituado al estudio del desarrollo del saber científico o filosófico, la historia del arte ofrece un penoso e inquietante espectáculo, porque normalmente parece desplazarse, no hacia delante, sino hacia atrás. En ciencia y filosofía, los sucesivos cultivadores del mismo campo producen (...) un adelanto, y un movimiento retrógrado supone siempre una solución de continuidad. En arte, en cambio, una escuela, una vez establecida, se deteriora normalmente al seguir su marcha. Logra la perfección en su género con una impresionante explosión de energía, en acción demasiado rápida para que los ojos del historiador la sigan. Nunca puede explicar ese movimiento o decirnos con exactitud cómo se produjo. La perfección lograda no educa ni purifica el gusto de la posteridad; lo pervierte (...) En la medida en que hay una ley perceptible en la historia del arte colectivo, es, como la ley de la vida del artista individual, una ley, no de progreso, sino de reacción. En grande o en pequeño, el equilibrio de la vida estética es permanentemente inestable".

Se pueden compartir o no la 'metafísica del espíritu cognoscitivo' de Collingwood, pero sus observaciones son difíciles de refutar: el arte parece evolucionar de un modo muy diferente a otros campos de la cultura con los que, sin embargo, está muy relacionado. En efecto, la aparición de una escuela o estilo suele ser veloz en términos históricos (incluso a la escala de una vida humana), e ir seguida de una etapa estable que puede ser muy duradera y parecer de inmovilidad o estancamiento, para desembocar en un colapso casi repentino o en aparente decadencia ignominiosa. En cualquier caso, no cabe hablar de progreso estético en el sentido aplicado a la ciencia y la técnica, que consiste -como insistía Karl Popper- en la acumulación de nuevos conocimientos,como las teorías que se añaden o desplazan a las anteriores.

Sin embargo, la primera impresión puede ser muy distinta. Thomas S. Kuhn ([1962] 1986) inició su famosa investigación sobre las revoluciones científicas con la hipótesis de que la historia del arte podía aportar un modelo heurístico para la ciencia, pero concluyó que arte y ciencia son muy diferentes. Hay una separación esencial entre aquellos conocimientos que se acumulan y progresan y que, por tanto, son ciencia y los que, siendo también conocimiento, no se acumulan y por consiguiente no progresan: "¿Progresa un campo debido a que es una ciencia, o es una ciencia debido a que progresa?" (Kuhn [1962] 
1986, 251). La ciencia no es pues algo dotado de cierta esencia ontológica, sino cualquier conocimiento acumulativo y progresivo. Distinción de gran relevancia porque modifica la idea de ciencia, y también del arte, como cierto tipo de 'sistema'. En su lugar, ciencia es aquella investigación que evoluciona formando, a través de 'revoluciones' del modelo normal, nuevos paradigmas más explicativos de los fenómenos que estudia.

Los conocimientos como el estético o artes pueden describirse como una sucesión de paradigmas (los estilos históricos o cánones), pero no desembocan en un nuevo paradigma que subsuma a los precedentes. En la historia del arte,lo habitual hasta la modernidad era que cada nuevo canon (que aquí podemos llamar paradigma) hiciera borrón y cuenta nueva del precedente. La modernidad parece una excepción, porque tampoco hay un paradigma inclusivo o sintético de los anteriores, pero sí una vida paralela de tendencias rivales o muy distantes (por ejemplo, el arte conceptual, el body-art, la pintura y escultura realista tradicionales). Una situación que, como observa Kuhn, no podría darse en la ciencia sin impedir el avance del conocimiento: imaginemos que la física newtoniana fuera rival de la relativista y no un paradigma subsumido en éste, en cuyo caso habría dos físicas rivales en vez de una física normal. Pero en la evolución estética lo habitual es que las nuevas reglas canónicas emerjan con gran rapidez y después apenas cambien en largos periodos, hasta entrar en una crisis de la representación y desaparecer o sufrir una fuerte mutación.

Sabemos o entendemos cómo y con qué reglas trabajaban Eurípides o Shakespeare, pero no cómo producir con ellas nuevas obras dramáticas no ya mejores, sino al menos de calidad comparable en vez de imitaciones inferiores. También sirve el ejemplo bien conocido de los talleres en los que trabajan los artistas antiguos con grupos de aprendices que podían ser muy numerosos, dotados de sistemas de producción muy eficaces, hasta el punto de que algunos cuadros firmados por Rubens y otros artistas apenas tengan más pincelada del maestro que la firma, problema de atribución que conocen muy bien los expertos. En el arte contemporáneo ocurre parecido: el empleo de materiales y técnicas industriales, al estilo del constructivismo, del racionalismo (uno de los ideales de Moholy-Nagy era producir artefactos dictando por teléfono sus características a un taller) y del minimalismo no facilita la producción de obras 'mejores' que las de referencia; en el polo contrario, las técnicas 'espontáneas' de un Jackson Pollock no facilita que cualquiera supere sus obras, e incluso el propio Pollock vivió una fuerte crisis personal, resuelta por su muerte, tras el veloz agotamiento de su técnica pictórica. Duchamp también mostró esta aparente paradoja introduciendo la técnica más simple, 
radical y devastadora posible para la teoría del arte: escoger un objeto banal y convertirlo en ready-made mediante la acción de firmarlo.

Dicho de otro modo (y como ya observó negativamente Platón a propósito de la "inspiración divina" de los poetas): el arte puede tener su teoría y técnica, pero éstas no son productivas en el sentido de servir como reglas capaces de producir nuevas y mejores obras, a diferencia de lo que ocurre en el resto de la tecnología. Para diseñar un automóvil mejor basta con conocer a fondo su tecnología, pero no así en las artes, cuyas teorías son más bien descriptivas.

Hay otras diferencias evidentes. En ciencias no aparecen fenómenos de recurrencia, o retrógrados, como "renacimientos" o movimientos de primitivismo, bastante frecuentes en la historia del arte. Quizás renacimientos y regresiones sean posibles y recurrentes debido a que no hay un corpus de conocimientos transmisible, ni métodos de verificación o falsación experimental o predictiva. El arte usa sus técnicas para desarrollar representaciones creativas de un sentido muy diferente al científico. Es la diferencia entre decir de un círculo que es bello o representa la forma perfecta, o definirlo como el cuadrado del radio multiplicado por $\pi$. La definición matemática no tiene la intensidad emocional de la estética, pero es la que permite el despegue de la geometría científica, es decir, acumulativa y progresiva.

Los conocimientos estéticos se experimentan emocionalmente (son sentidos) y se reviven de manera distinta en cada oportunidad (histórica y subjetiva), dejando poco que acumular aparte de la propia historia del arte. El canon estético parece más un marco de referencias y un sistema de instrucciones sobre cómo producir artefactos y situaciones para obtener determinadas experiencias, sin garantías de éxito, que un conjunto de saberes sobre tales experiencias que permita reproducirlas fielmente. Los conocimientos estéticos parecen describir bucles autorreferenciales y recurrentes incapaces de ascender a otro nivel cognitivo. Pueden alcanzar la plenitud en su propio mundo simbólico, pero no sirven para entender mundos diferentes.

\section{UNA EVOLUCIÓN ESTOCÁSTICA}

Los ejemplos de aparición brusca, estabilidad y crisis repentina son numerosísimos. Consideremos el arte paleolítico: los datos, cada vez más numerosos 
según se estudian más yacimientos, sugieren que aparece de una manera casi repentina hace entre 35.000 y 30.000 años. Luego consigue la increíble estabilidad de más de 20.000 años de duración. Pero desaparece bruscamente en el neolítico, sustituido por formas estéticas muy diferentes. Durante esos largos milenios se pueden registrar cambios y variaciones regionales notables, como los llamados estilos auriñaciense, soloutrense y magdaleniense, o el hecho de que haya regiones con 'venus' o estatuillas antropomórficas y otras sin ellas, como la Península Ibérica (exenta hasta el momento). Pero la coherencia canónica de esas representaciones es evidente en un inmenso territorio y lapso de tiempo. Es más, hay un gran consenso en que los anónimos artistas paleolíticos lograron desde el principio cotas insuperables de excelencia y pericia, como en la cueva de Chauvet $^{1}$, por ejemplo; hay otros yacimientos posteriores admirables, pero no mejores que el de Chauvet.

Junto a la duración del fenómeno, lo más llamativo es su brusca aparición y desaparición. Resultan contrarias a la intuición porque tendemos a creer "normales" las evoluciones graduales o heurísticas. Sin embargo, la evolución heurística o gradual brilla por su ausencia en la historia del arte. Lo corriente es el cambio brusco e intempestivo o a saltos, técnicamente, cambio estocástico. El caso del arte paleolítico es tan llamativo, y por proyección el del arte y su historia errática en general, que ha interesado a los mejores estudiosos de la evolución. Observa al respecto Sthepen Jay Gould $(2004,983)$ que "los logros culturales pueden acumularse progresivamente aunque la biología darwiniana permanezca inalterada. (...) Pero si es así (...) lo que observamos, en la muestra total disponible, es algo análogo a la historia del arte occidental desde Fidias hasta Picasso: muchos cambios de estilo, pero ningún progreso direccional; nada de la transición entera desde el primer homínido que perforó un diente de oso y de lo colgó del cuello hasta Les demoiselles d'Avignon".

Es el caso del arte del Egipto faraónico: aparece con rapidez a inicios del tercer milenio a.C. y dura hasta los siglos I o II d.C. En ese intervalo de más de 3.000 años hubo cambios y evolución, pero mantuvo una poderosa unidad desde el brusco comienzo. Hubo cambios notables en arquitectura, pero la escultura y la pintura -la iconografía y el simbolismo en general- se mantuvieron asombrosamente fieles a los cánones originales ${ }^{2}$ pese a las profundas turbulencias políticas y la evolución social e ideológica.

Parecido esquema de sucesión eclosión-estabilidad-colapso sigue el canon greco-romano, desde el surgimiento en el siglo VIII a.C en Grecia ${ }^{3}$ a su disolución, bastante vertiginosa, en el nuevo arte cristiano (occidental y bizantino) 
a partir del siglo $\mathrm{V}$ d.C, y en Oriente Medio también en el nuevo arte islámico. Es muy notable que el canon griego subsistiera a través de profundad modificaciones del sistema sociopolítico, porque la polis clásica donde alcanza la madurez poco tuvo que ver con los reinos helenísticos autocráticos posteriores, ni con el Imperio Romano.

Así que parece haber un modelo de evolución estética resumible así:

i. Fase de formación del canon, con sus reglas y valores simbólicos para determinados fines de representación. El arte griego, por ejemplo, es antropocéntrico y el resto de la naturaleza importa mucho menos; tiene un fuerte concepto de mímesis; adopta reglas muy claras de armonía, proporción y geometría.

ii. Fase de permanencia y equilibrio del canon, en el que hay cambios e innovaciones pero, en cualquier caso, coherentes con las reglas canónicas vigentes.

iii. Fase de crisis y colapso del canon que deja paso a otro diferente. El colapso puede ser tan drástico como el que separa la cultura micénica de la griega antigua, o el Egipto faraónico del islámico, y sin mediar ninguna sustitución o 'invasión' de poblaciones a pesar de las explicaciones tradicionales en ese sentido.

En esquema, algo parecido a esto:

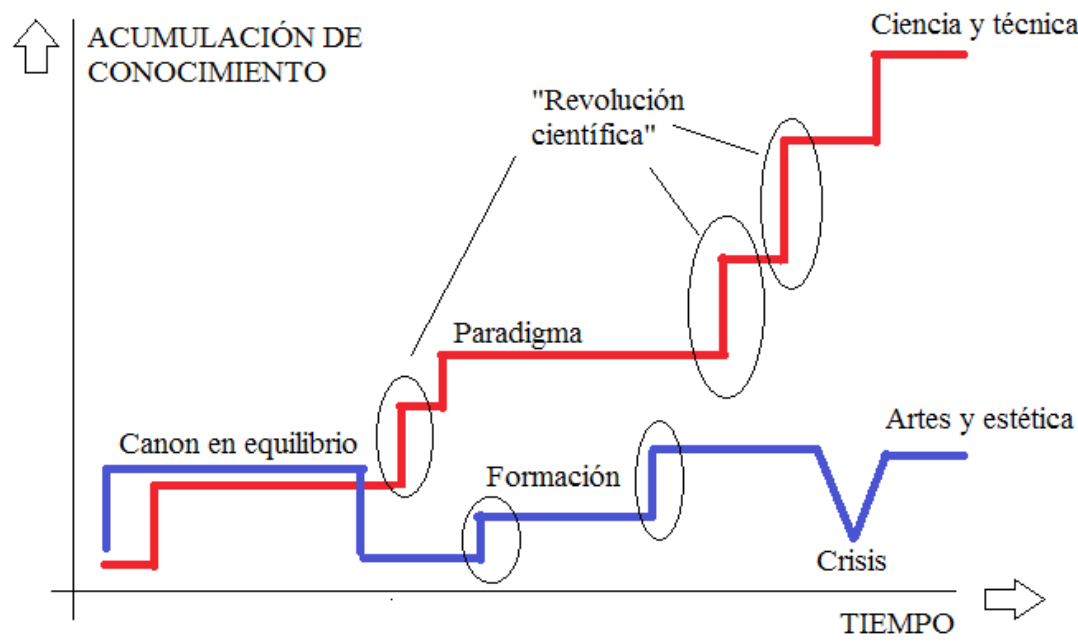


Aunque desde un punto de vista filosófico, ideológico o científico no lo parezca, estéticamente el nuevo canon no es mejor o peor que el precedente: sólo es otro. $Y$ no se trata de un punto de vista relativista, sino más bien de reconocer el hecho de la capacidad estética de las sociedades para inventar nuevos modelos de representación prescindiendo de los precedentes e incluso olvidándolos por completo. En el caso del arte moderno conocemos muy bien las rupturas que conducen del academicismo y la pintura pompier al impresionismo y sus derivaciones, o de la Escuela de París al expresionismo abstracto americano, y de éste a las nuevas tendencias depor-art, arte de acción, body-art, minimalismo, etc. Lo que encontramos son saltos, cambios de corta duración considerados desde una perspectiva histórica.

Es cierto que la historia estética ofrece numerosos ejemplos de "renacimientos" en los que podría parecer que se 'restablece' o 'restaura' un canon clásico perdido, como si celebrara una historia circular con ciclos renovados de nacimiento, vida, muerte y resurrección. Pero este sugestivo eterno retorno es una ilusión. Se desvanece cuando se comprueba que tales 'renacimientos' inevitablemente son reinterpretaciones completamente innovadoras de algunos restos o aspectos parciales del canon antiguo, como ocurre con el Risnacimento della antiquité de Italia en el siglo XV. Pese a su grandiosidad sólo fue otro episodio, aunque paradigmático, en la sucesión de los 'renacimientos' del clasicismo iniciados ya en el siglo VIII en Europa occidental (Panofsky [1960] 1985).

Lo mismo puede decirse de muchos periodos 'primitivistas': la vuelta a un estadio prístino e ingenuo de artes adánicas, desprovistas de cultura, es otra ilusión.

El único periodo en que parece haber acumulación de cánones diferentes es el moderno. A partir de la segunda mitad del siglo XIX, en el arte occidental y pronto en el mundial coexisten e interaccionan corrientes estéticas completamente diferentes. La carrera de artistas como Pablo Picasso es una sucesión de constantes cambios de estilo, a veces drásticos, donde lo único permanente es la personalidad del artista y su fama.

El moderno es más bien un anti-canon y puede que inaugure otro modelo de evolución estética que incorpora la competencia y mestizaje de corrientes diferentes en lugar de la sustitución y la 'superación' hegeliana o el olvido, pero parece demasiado pronto para decir nada concluyente al respecto. Tengamos en cuenta que la teoría estética moderna llegó a su madurez, y comenzó su 
proliferación, con la filosofía del arte de Hegel y sus tres estadios de evolución histórica que, tras el arte simbólico, clásico y romántico, desembocan en el momento de 'muerte del arte' cuando pierde su capacidad para revelar formalmente aspectos del Espíritu universal. Ignorando la teoría de ese fin o muerte del arte ideal, y quizás paradójicamente animada por esa expulsión de la Historia, coincidiendo con el éxito de la filosofía hegeliana la explosión de creatividad volvió a ser brusca y de extraordinaria diversidad. Como señala Valeriano Bozal respecto al periodo crítico de 1900-1910: "Frente a la fisonomía que éstos ofrecen en los años veinte y treinta, los diez primeros parecen dominados por la diversidad y la diferencia. No hay una línea común, única, hay varias, en ocasiones solo fragmentos, que parecen acumularse sin excesivo orden"(1991, 22).

Como si de un inesperado fenómeno de causalidad descendente se tratara (un proceso donde la causa conduce a la fase de origen en vez de a una fase ascendente, rompiendo con la lógica del progreso), Picasso subrayó la importancia de "aprender a dibujar como un niño" para dar con la esencia del arte inocente, sin contaminar por cultura y educación. No faltan voces más radicales aún, como la de Jean Dubuffet (Citado en Thévoz [1975] 1981, 5), empeñado en que el 'arte puro' o art brut no hay que buscarlo en las instituciones (museos, galerías, crítica) ni entre los artistas profesionales (como él mismo), autores de "una versión impostada, cuando no debilitada y falsificada" del "arte puro', sino entre los niños, los alienados mentales y los pueblos nativos no 'aculturados' o 'primitivos'.

La premisa subyacente a la conjetura de la invariancia estética, la persistencia resiliente de ciertas formas con valores y emociones inmanentes, es que la experiencia estética y el arte que la procura mantienen y transmiten determinados saberes de valor universal (necesarios, es decir trascendentales) con independencia de circunstancias culturales, sociales o personales. La recurrencia de tales movimientos anima a pensar en tales términos y a distinguir, por ejemplo, momentos clásicos, manieristas y barrocos en ámbitos tan distintos como el arte griego, chino o maya, de manera que cánones muy diferentes seguirían patrones evolutivos comparables, cuando menos. De alguna manera, cada canon reproduciría en su propia ontogénesis toda la filogenia del arte, e incluso ciertos artistas sintetizarían en su propia evolución la historia completa del arte desde la prehistoria hasta el presente y una segunda 'muerte del arte', como quiso Jorge Oteiza (sin ser el único ${ }^{4}$, ni mucho menos). 
Sin embargo, un canon estético se parece más a un marco de referencias y a un sistema de instrucciones sobre cómo producir y juzgar determinadas obras y experiencias que a un conjunto de saberes sobre el significado de tales experiencias. En realidad es mucho más interesante ver este fenómeno como una combinación de la autoreferencialidad y polisemia típica de las obras de arte y de las experiencias estéticas.

La autoreferencialidad consiste en que la obra (o la experiencia) remita constantemente a su presencia formal con independencia de los significados diversos que puede generar o connotar, la polisemia. Pero debido a la polisemia, un artefacto estético es, o puede ser, y sin dejar de presentarse como su propio referente u objeto semiótico, varias cosas a la vez, servir para varios propósitos de significación. Un poema épico como la llíada es un monumento poético en sí mismo, es decir, es autoreferencial-especialmente para nosotros, desarraigados de su cultura original- con independencia de que para los antiguos griegos fuera a la vez una enciclopedia didáctica sobre política, guerra, poder, religión y una porción de cosas de todo tipo, desde cómo hacerse una lanza hasta cómo dirigir una asamblea de caudillos guerreros, pasando por la cartografía de la Hélade del llamado 'catálogo de las naves'.

También las metáforas poéticas sirven como modelo heurístico y propedéutico para cualquier metáfora aplicada a cualquier otro campo, de la política a la ciencia. La operación de transferencia de significado que sirve para acuñar la expresión poética "cuando la Aurora de dedos de rosa" de los poemas homéricos para designar el amanecer es en puridad la misma que la del experimento mental del Gato de Schrödinger para la superposición cuántica. Las metáforas poéticas se dirigen en primer lugar a las emociones, pero constituyen el patrón lingüístico y cognitivo de cualquier otra analogía, en tanto que modo de transferir significado de un objeto a otro diferente mediante el predicado y la inferencia. Está fuera de toda duda que las metáforas poéticas son las primeras que aparecen en la historia de la cultura, del modo en que el pensamiento de Homero y Hesíodo precede e influye sobre el de sofistas y presocráticos, y el pensamiento de éstos al de Platón y Aristóteles. Por tanto, podemos pensar que conocimientos estéticos como las cualidades cognitivas de la metáfora y la analogía son condición necesaria para la evolución de tipos de pensamiento más elaborados, como el retórico, filosófico y científico-técnico.

En resumidas cuentas, ¿qué peculiaridad de la estética explica una evolución tan diferente a la de la ciencia olas instituciones sociopolíticas y económicas? La hipótesis que someto a consideración es que la cognición estética presenta 
cualidades y propiedades inmanentes que configuran su modelo evolutivo y su papel en la evolución de la cultura.

\section{UNA EXPLICACIÓN COGNITIVA}

Como es sabido, aunque aún estemos lejos de comprender todas sus implicaciones, la evolución cultural surge de la evolución biológica general que actúa sobre la eficacia de la reproducción y transmisión de patrimonio genético, pero discurre bajo una lógica adaptativa muy diferente. Desde que aparece la conciencia, la cultura es en buena medida el resultado de opciones conscientes y ya no solamente de instintos y opciones inconscientes, aunque éstas sigan jugando un papel importante en la actividad de la mente. Pero la diferencia abierta es tan grande que, según Stephen Jay Gould (2004), mientras la evolución natural es darwinista la cultural es lamarckiana, lo que significa que la transmisión de conocimiento adaptativo es más decisiva que la de adaptaciones del acervo genético. Por eso explicarlo todo, del lenguaje a la economía de mercado pasando por las religiones y las artes, como "adaptaciones evolutivas para mejorar el éxito reproductivo" básicamente instintivas, es una mera petición de principio.

La perspectiva cambia si consideramos la evolución del canon estético como un fenómeno emergente en el curso de la evolución cultural. Los sistemas y fenómenos emergentes requieren aumento de complejidad y de información para ascender de nivel. Tanto la mente humana,que emerge de la actividad cerebral, como la capacidad de producción de cultura de esa mente, son fenómenos emergentes de este tipo. El aumento de complejidad del córtex cerebral no condujo a una conducta animal más sofisticada, sino a una mente cualitativamente distinta. Por ejemplo, el lenguaje humano es mucho más que un sistema de señales para transferir información como el que tienen muchas especies animales y vegetales; el nuestro es un lenguaje complejo, creativo y polisémico en grado sumo. Pero en la evolución de los sistemas emergentes, imprevisibles y de origen estocástico por definición, aparecen efectos completamente inesperados.

Se ha discutido mucho la relación causal entre encefalización y hominización. Lo que está fuera de dudas es que facilitó la emergencia de nuevos y revolucionarios procesos cognitivos como la empatía, la conciencia como identidad 
del yo o sí-mismo, y el desarrollo de la abstracción simbólica a través del lenguaje. Una mente capaz de pensar en sí misma como protagonista de su existencia es una mente que piensa y experimenta la vida como una narración. El hecho de que el cerebro produzca de modo incesante imágenes de sus percepciones corporales que se traducen en imágenes mentales mediante un cambio de fase y nivel, del neurológico al simbólico (Marcus 2005; Damasio 2010), explica el origen de la conciencia, del lenguaje humano y del pensamiento simbólico. Éste incluye la invención y empleo de un canon estético que facilita y regula la vital representación por analogía: la clave de la temprana aparición de prácticas e instituciones estéticas en la cultura humana, y su curioso modo de evolucionar, radica en nuestro pensamiento analógico, necesitado de figuras, formas, representaciones simbólicas y su correspondiente interpretación. Obviamente, es mucho más fácil que el pensamiento analógico aparezca y evolucione unido al propósito de satisfacer la emoción de placer que llamamos estético -disfrutar de las sensaciones, como dijo Aristóteles-, que a la satisfacción intelectual del pensamiento más abstracto.

No veo aceptable la teoría bioadaptativa de Denis Dutton (2010), apoyada con entusiasmo por el psicólogo evolutivo Steven Pinker y que explica los fenómenos estéticos como estrategias adaptativas de seducción y éxito sexual para atraer y elegirla pareja más conveniente, naturalmente instintivas e inconscientes en gran medida. Dutton ataca vigorosamente el absurdo del constructivismo social y subraya con acierto la continuidad histórica y universalismo de ciertas inclinaciones estéticas básicas, pero a partir de éstas las diferencias en materia estética son tantas como permiten la educación, la tradición cultural y la experiencia y capacidad de cada cual. Y añadamos la objeción que aporta la evolución histórica del arte: ni hay acumulación de conocimiento, como señala Kuhn, ni de adaptaciones culturales progresivas, como señala Gould.

Me parece posible una explicación naturalista de la evolución estética, alternativa a la darwinista ingenua (y por supuesto a la idealista hegeliana y sus múltiples derivadas), a partir de las siguientes premisas de orientación cognitiva:

1. La cognición estética está asociada a la transformación de imágenes cerebrales, surgidas de las sensaciones y las emociones implicadas (como las de placer y repulsión), en imágenes mentales de significado simbólico y cognitivo superior.

2. La cognición estética consiste en el empleo intencional de los versátiles sistemas psicosomáticos que vinculan sensaciones, percepciones e imágenes con memoria, emociones y sentimientos. 
3. El procesamiento de las imágenes mentales produce las analogías y representaciones del pensamiento simbólico. La naturaleza metafórica del pensamiento descansa en la capacidad estética (o poética y retórica) para imaginar, buscar y emplear analogías como los iconos, símbolos, representaciones, metáforas, alegorías y relatos de todo tipo.

4. La capacidad estética juega un papel triple en el desarrollo de la cognición:

a. entrenando la sensibilidad sensorial, perceptiva y emocional.

b. formando la imaginación analógica multipropósito.

c. elaborando el "yo autobiográfico", núcleo de la identidad humana, individual y social.

5. El canon estético (las artes) fundamenta una comunidad de representación del mundo comparable a la comunidad de lenguaje (Valeriano Bozal 1987, 24), puesto que permite consensuar una determinada representación de los fenómenos, sensaciones y emociones.

6. El canon estético es un sistema emergente de nivel intermedio surgido de otro sistema emergente de nivel más básico, la cultura, emergente a su vez de la mente humana (con sus atributos de conciencia, pensamiento y lenguaje) surgida de la evolución natural.

Las peculiaridades evolutivas de las artes pueden explicarse por su papel en la configuración de una 'comunidad de representación', una especie de nivel intermedio entre mente individual y cultura social. Una vez instaurada una determinada comunidad de representación tras una 'explosión creativa', puede convertirse en un sistema estético estable que forma parte muy importante de la cultura como sistema convencional de representación propio, transmitido en equilibrio más o menos dinámico durante largos periodos de tiempo aun cuando conocimiento, sociedad e instituciones experimenten cambios más drásticos en ese mismo periodo.

\section{Referencias}

Bozal Fernández, Valeriano. 1987. Mímesis: las imágenes y las cosas. Madrid: Visor

- 1991. Los primeros diez años. 1900 - 1910, los orígenes del arte contemporáneo. Madrid: Visor 
Collingwood, Robin George. 1922. Speculum mentis or The map of knowledge. Oxford UK: Clarendon

Damasio, Antonio. 2010. Y el cerebro creó al hombre. ¿Cómo pudo el cerebro generar emociones, sentimientos, ideas y el yo? Traducción de Ferran Meler Orti. Barcelona: Galaxia Gutemberg

Dutton, Denis. 2010. El instinto del arte: Belleza, placer y evolución humana. Traducción de Carme Font Paz. Barcelona: Paidós

Gould, Stephen Jay. 2004. La estructura de la teoría de la evolución. Traducción de Ambrosio García Leal. Barcelona: Tusquets

Kemp, Barry J. (1989) 1992. El antiguo Egipto: Anatomía de una civilización. Traducción castellana de Mónica Tussel. Barcelona: Crítica

Kuhn, Thomas S. (1962) 1986. La estructura de las revoluciones científicas. Traducción de Agustín Contín. Madrid: Fondo de Cultura Económica

Marcus, Gary. (2003) 2005. El nacimiento de la mente: Cómo un número pequeñísimo de genes crea las complejidades del pensamiento humano. Revisión científica a cargo de Ignacio Morgado Bernal. Barcelona: Ariel

Martínez Gorriarán, Carlos. 2011. Jorge Oteiza, hacedor de vacíos. Madrid: Marcial Pons

Osborne, Robin. 1998. La formación de Grecia. 1.200-479 a.C. Traducción castellana de Teófilo de Lozoya. Barcelona: Crítica

Panofsky, Erwin. (1960) 1985. Renacimiento y renacimientos en el arte occidental. Versión española de María Luisa Balseiro. Madrid: Alianza

Read, Herbert Edward. (1966) 1984. Historia de la Pintura Moderna. Capítulo final de CarolineTisdall y William Feaver Barcelona: Ediciones del Serbal

Thévoz, Michel. (1975) 1981. L'art brut. Genève: Skira

\section{Notas}

${ }^{1}$ La datación por radiocarbono de pigmentos de hollín de la cueva de Chauvet ha dado la fecha de $32.900 \pm 490$ AP.

${ }^{2}$ Para una visión de conjunto de las complejas raíces del canon egipcio y su evolución histórica, véase Barry J. Kemp ([1989] 1992).

${ }^{3}$ Para el origen de la cultura griega antigua tras el colapso micénico, sigue siendo muy útil el trabajo de Robin Osborne (1996). Trata de la cuestión de cómo surge un sistema cultural nuevo, con su canon estético, sobre las ruinas latentes de otro anterior.

${ }^{4}$ Véase en mi biografía acerca de una las trayectorias menos conocidas pero más paradigmática del tópico del paso de primitivismo a racionalidad constructivista y muerte de la vanguardia, en Carlos Martínez Gorriarán (2011). 